\title{
Topological control of nitric oxide secretion by tantalum oxide nanodot arrays
}

\author{
Udesh Dhawan ${ }^{1}$, Chia Hui Lee ${ }^{1}$, Chun-Chung Huang ${ }^{1}$, Ying Hao Chu' ${ }^{1}$ Guewha S. Huang², Yan-Ren Lin ${ }^{3}$ \\ and Wen-Liang Chen ${ }^{4}$
}

\begin{abstract}
Background: Nitric oxide (NO) plays a very important role in the cardiovascular system as a major secondary messenger in signaling pathway. Its concentration regulates most of the important physiological indexes including the systemic blood pressure, blood flow, regional vascular tone and other cardiac functions. The effect of nanotopography on the NO secretion in cardiomyocytes has not been elucidated before. In this study, we report how the nanotopography can modulate the secretion profile of $\mathrm{NO}$ and attempt to elucidate the genetic pathways responsible for the same by using Tantalum Oxide nanodot arrays ranging from 10 to $200 \mathrm{~nm}$. A series of nanodot arrays were fabricated with dot diameter ranging from 10 to $200 \mathrm{~nm}$. Temporal NO release of cardiomyocytes was quantified when grown on different surfaces. Quantitative RT-PCR and Western blot were performed to verify the genetic pathways of NO release.
\end{abstract}

Results: After hours 24 of cell seeding, NO release was slowly enhanced by the increase of dot diameter from $10 \mathrm{~nm}$ up to $50 \mathrm{~nm}$, mildly enhanced to a medium level at $100 \mathrm{~nm}$, and increase rapidly to a high level at $200 \mathrm{~nm}$. The temporal enhancement of NO release dropped dramatically on day 3. On day 5, a topology-dependent profile was established that maximized at $50 \mathrm{~nm}$ and dropped to control level at $200 \mathrm{~nm}$. The NO releasing profile was closely associated with the expression patterns of genes associated with Endothelial nitric oxide synthase (eNOS) pathway [GPCR, PI3K, Akt, Bad, Bcl-2, NFkB(p65), eNOS], but less associated with Inducible nitric oxide synthase (iNOS) pathway (TNF-a, ILK, Akt, IKBa, NFKB, iNOS). Western blotting of Akt, eNOS, iNOS, and NFKB further validated that eNOS pathway was modulated by nanotopology.

Conclusions: Based on the findings of the present study, 50, $100 \mathrm{~nm}$ can serve as the suitable nanotopography patterns for cardiac implant surface design. These two nanodot arrays promote NO secretion and can also promote the vascular smooth muscle relaxation. The results of this study can improve the heart stent design in the medical treatments.

Keywords: Tantalum oxide, Nanodots, Cardiomyocytes, eNOS, iNOS, Signaling pathway

\section{Background}

Nanotopography affects cell physiology. But the effects of different size of nanosurfaces on different cells are very inconsistent. Topographies like nanodots [1-4] nanoislands [5], nano-concave [6], nanocrystalline [7] diamond, nano-groove [8-11] nanotube [12], nano-ridge $[13,14]$, nanopore [15] have been reported to affect the

\footnotetext{
*Correspondence: wenurea@yahoo.com.tw

${ }^{4}$ Department of Biological Science and Technology, National Chiao Tung University Hsinchu, 1001 University Road, Hsinchu 300, Taiwan, ROC Full list of author information is available at the end of the article
}

cell physiological behavior, including biocompatibility, cell growth, migration and cell adhesion. Previous studies conducted on the interaction of the cells with quartz surfaces have shown change in the surface area of the cells [16]. Change in the morphologies of osteoblasts on interaction with substrates has also been shown $[17,18]$. Roughness of Titanium substrates has also been seen to modulate the adhesions of the cells to the nanosurface [19]. We have shown in our previous studies that cells have maximum adhesion area on $50 \mathrm{~nm}$ nanodots whereas 100 and $200 \mathrm{~nm}$ always trigger off immune 
response [20] after day 3. For nanoislands, the cytoskeletal organization, cell growth and proliferation are highly enhanced on size smaller than $27 \mathrm{~nm}$ but decreased cell physiological indexes are observed for size greater than $80 \mathrm{~nm}$ [21]. Previous studies have shown that C3A cells spread and grew confluent with elongated and aligned morphology along $100 \mathrm{~nm}$ nanogrooves [22] Similar studies have also been conducted on Titanium dioxide nanotubes $\left(\mathrm{TiO}_{2}\right)$ for $15 \mathrm{~nm}$ spaced incubation but deteriorated cell proliferation has been observed on $350 \mathrm{~nm}$ nanosurface [15].

We have reported in our previous studies on NIH3T3 cells that nanodot arrays with 10-200 nm nanodots modulate cell adhesion and induce an apoptosis like abnormality [2]. The apoptosis like abnormality became evident in $200 \mathrm{~nm}$ nanodots after day 1 . The abnormality starts to show on $50 \mathrm{~nm}$ after day 3.40 and $75 \mathrm{~nm}$ nanopores promoted cell adhesion and migration in fibroblast by controlling expression of integrins and ERK $1 / 2$ in a time dependent manner [4]. A lot of variability in the cell morphology, migration ability, gene and protein expression was found after 12, 24, 48, hours 72 and became indistinguishable after incubation for hours 120 .

Previous studies conducted on cardiomyocytes have shown maximum growth, proliferation and extended morphology on $50 \mathrm{~nm}$ nanodot arrays after day 3. Maximum growth and adhesion shifted to $100 \mathrm{~nm}$ after incubation for hours 120 [3]. This shows that nanotopography regulates cell physiology not only in the size dependent manner but also in a time dependent manner.

Nitric oxide (NO) plays a very important role in the cardiovascular system as a major secondary messenger in signaling pathway. It is a key signaling messenger in the cardiovascular system. Its concentration regulates most of the important physiological indexes including the systemic blood pressure, blood flow, regional vascular tone and other cardiac functions. It also maintains the vascular integrity by inhibiting the platelet aggregation and vascular smooth muscle proliferation [23, 24]. Enough NO secretion enhances vascular remodeling whereas its deficit induces attenuation in vascular remodeling [25]. It has previously been reported that conditions like atherosclerosis, hypertension, hypercholesterolemia and congestive heart failure are related to abnormal NO concentrations [26-28]. Thus, controlling NO concentration is of great importance in cardiovascular therapy and implants.

Topography has been reported to regulate the physiological behavior of cardiomyocytes. NO is a major secondary messenger in the signal transduction pathway of cardiomyocytes [29]. However, the effects of topography on NO secretion have not been elucidated. Here, were propose a novel method by which NO levels in rat cardiomyocyte cell line $\mathrm{H} 9 \mathrm{c} 2$ are modulated in response to different size of the tantalum oxide nanodots. This is the first study which aims to study and co-relate the expressions of eNOS, iNOS in response to a nanosurface. We also studied the modulation in expression of eNOS and iNOS genes in response to the nanosurface by qPCR and the change in protein expression of Akt, eNOS, iNOS, p65 by Western Blot. We have attempted to elucidate the molecular pathways of iNOS, eNOS related cell injury as an in vitro model. We believe that understanding the response of the cell to its external environment and the upregulation or downregulation of signaling pathway in response to different size of nanodots will play an integral role in designing cardiac implants with minimal side effects and increased Bio-compatibility in the near future.

\section{Results}

\section{Fabrication of nanodot arrays}

Nanodots array were fabricated by anodic aluminum oxide (AAO) processing on aluminum tantalum-coated wafer (Fig. 1a). Tantalum oxide nanodots array with 10 , 50, 100, and $200 \mathrm{~nm}$ dot diameters were constructed on silicon wafer. The nanodot diameters $12 \pm 2.8$, $50.35 \pm 3.2,99.4 \pm 6.3$, and $206.7 \pm 6.5 \mathrm{~nm}$ were examined with scanning electron microscopy (SEM) (Fig. 1b). Dimensions of nanodots were well controlled and highly defined.

\section{Nitric oxide (NO) secretion exhibited a size dependent and time dependent profile}

H9c2 cardiomyocytes were cultured on different nanodot arrays (Flat, 10, 50, 100, $200 \mathrm{~nm}$ ). Aluminum coated substrate was considered as Flat. Cells treated with Lipopolysaccharide and Rapamycin served as positive and negative controls respectively. NO concentration was detected using Griess reagent system.

NO secretion profiles displayed a size dependent relation with the nanodot arrays. After day 1 incubation period, a parabolic profile of NO secretion was observed. It increased moderately from flat to $100 \mathrm{~nm}$ nanodots and abruptly on $200 \mathrm{~nm}$ nanodot arrays. The increase on $200 \mathrm{~nm}$ nanodots was found out to be six folds than the control group. After day 3, the parabolic profile of NO secretion adopted a hyperbolic profile. Maximum NO secretion was displayed by cells cultured on $100 \mathrm{~nm}$ arrays. After day 5, hyperbolic profile was consistent. However, this time, $50 \mathrm{~nm}$ showed maximum NO secretion. This change was noted to be 1.5 folds when compared to the control groups (Fig. 2).

NO secretion profiles were time-dependent. After hours 24 of incubation of the cardiomyocytes, maximum stimulation of NO secretion was displayed by $200 \mathrm{~nm}$ 


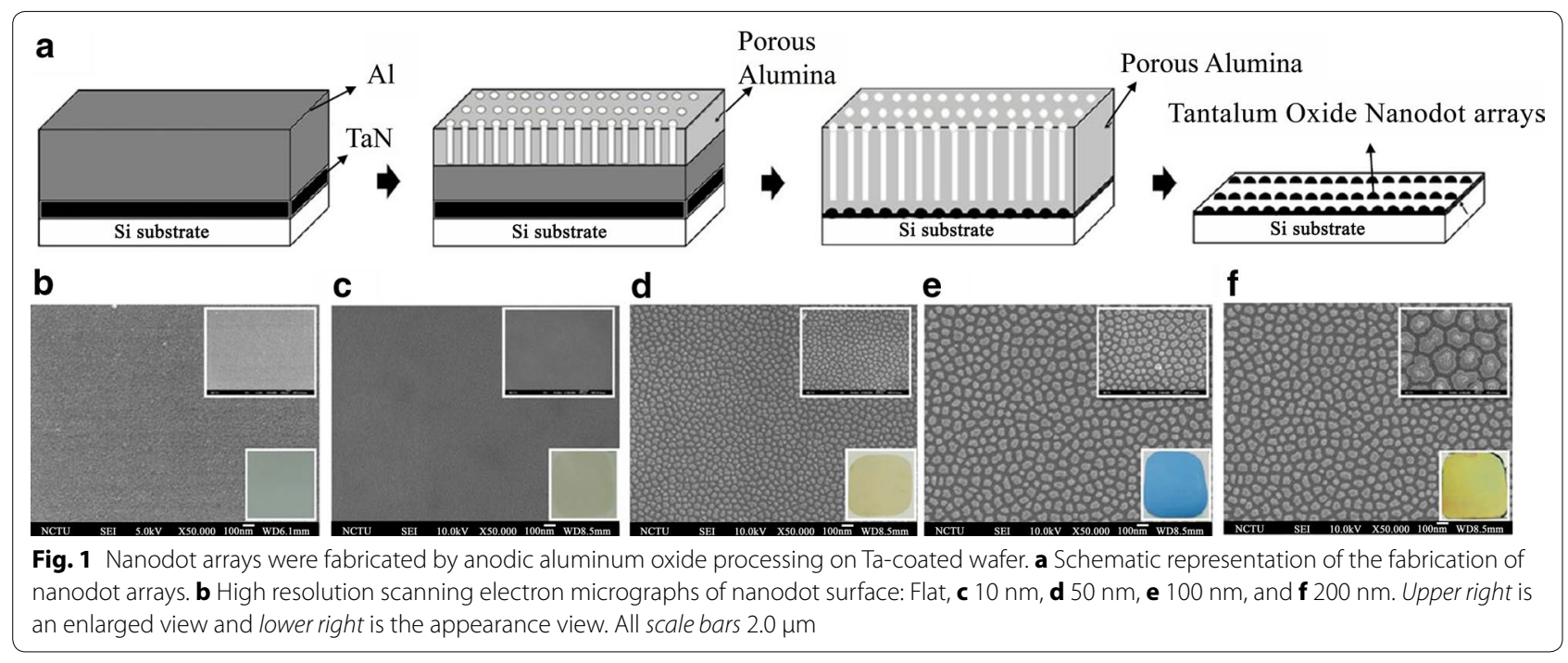

nanodot arrays. After hours 72, $100 \mathrm{~nm}$ arrays stimulated maximum NO secretion. After hours 120, the profile remained the same but the maximum stimulation was observed to be caused by $50 \mathrm{~nm}$ arrays. In summary, NO secretion was stimulated by the nanodot arrays in the cardiomyocytes in a time dependent and size dependent manner (Fig. 2).

\section{Association of NO release and eNOS pathway with qPCR}

The mRNA expression of eNOS pathway observed in H9c2 cardiomyocytes cultured on different nanodots was determined using qPCR (Fig. 3). According to real time PCR results, gene expression of Bad, p65 and eNOS corresponded with NO release (Fig. 3d, f, g). On day 1, Bad, p65 and eNOS were higher on $200 \mathrm{~nm}$ than on other surface. On day 3, those genes were higher on 10 and $100 \mathrm{~nm}$; on day 5 were higher on $10 \mathrm{~nm}$. The data shows apparent difference in Bad, p65. eNOS expression was correlated to NO production. In summary, with time course, the maximum amount of gene expression switched from 200 to $10 \mathrm{~nm}$.

\section{Association of NO release and iNOS pathway}

qPCR of genes associated with inflammation related iNOS pathway (TNF- $\alpha$, ILK, AKT, IкB $\alpha$, iNOS) in H9c2 cardiomyocytes was performed (Fig. 4). The mRNA expression of iNOS signaling pathway genes was determined using qPCR (Fig. 4). Over various days, we observed gene expression of cardiomyocytes cultured on $50 \mathrm{~nm}$ nanodot arrays was significantly less than other nanodots. According to real time PCR results, gene expression of ILK, IKB $\alpha$ and p 65 corresponded with gene regulation (Fig. 4b, d, e). However, the mRNA expression were less correlated to $\mathrm{NO}$ production.

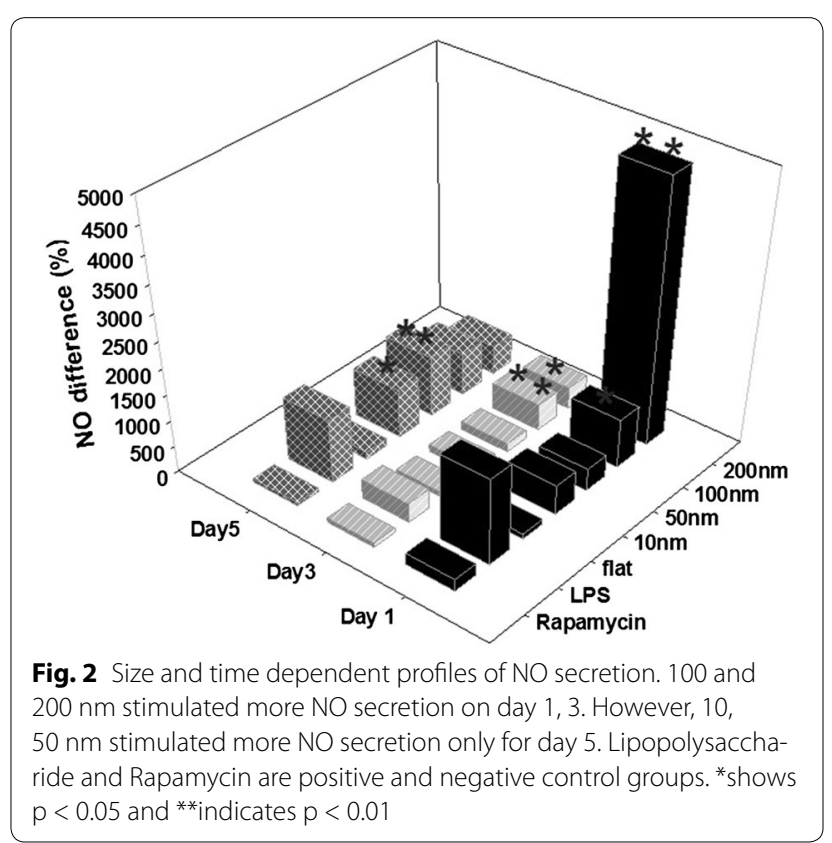

\section{Comparison of NO secretion profile with expression} patterns of genes associated with eNOS pathway by using Western Blot

The NO formation is regulated by the family of enzymes, Nitric oxide synthase (NOS) [30]. NOS have three main isoforms: neuronal NOS (nNOS), endothelial NOS (eNOS), and inducible NOS (iNOS). The cardiovascular diseases are mainly related with the eNOS and iNOS. It has previously been shown that the lipopolysaccharides and the cytokines regulate the iNOS present in the cells at the transcriptional level [31]. Some recent studies have also shown that in the iNOS pathway, NF-kB 

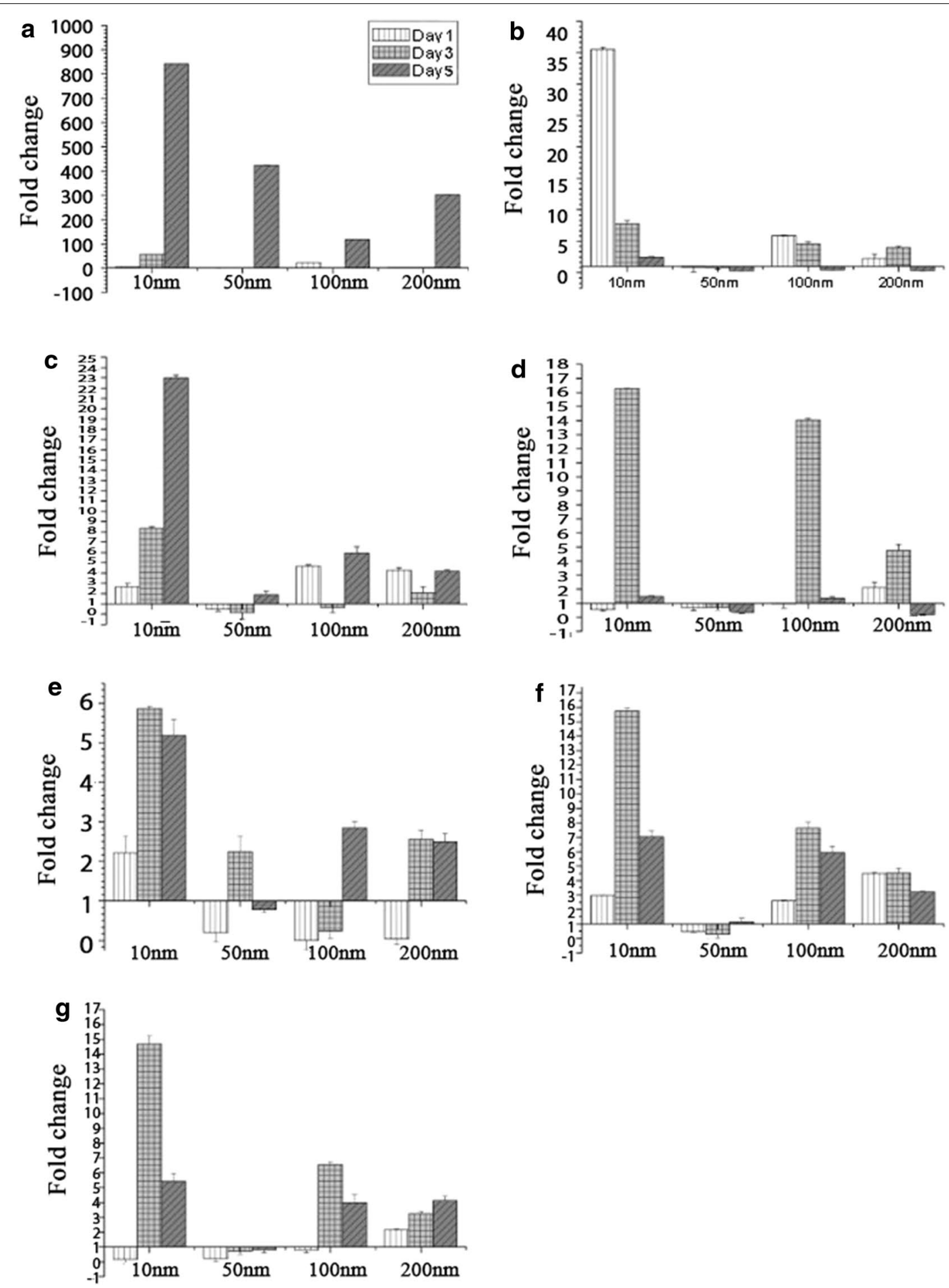

Fig. 3 Expression of eNOS genes in H9c2 on difference nanodots arrays by qPCR. H9c2 cells were cultured on flat, 10, 50, 100, and 200 nm nanodot arrays for day 1, 3, 5 before qPCR was performed. a GPCR expression, b PI3K expression, c Akt expression, $\mathbf{d}$ bad expression, e Bcl-2, f NFKB (p65) expression $\mathbf{g}$ eNOS expression. The mean \pm SD from at least 3 experiments is shown 

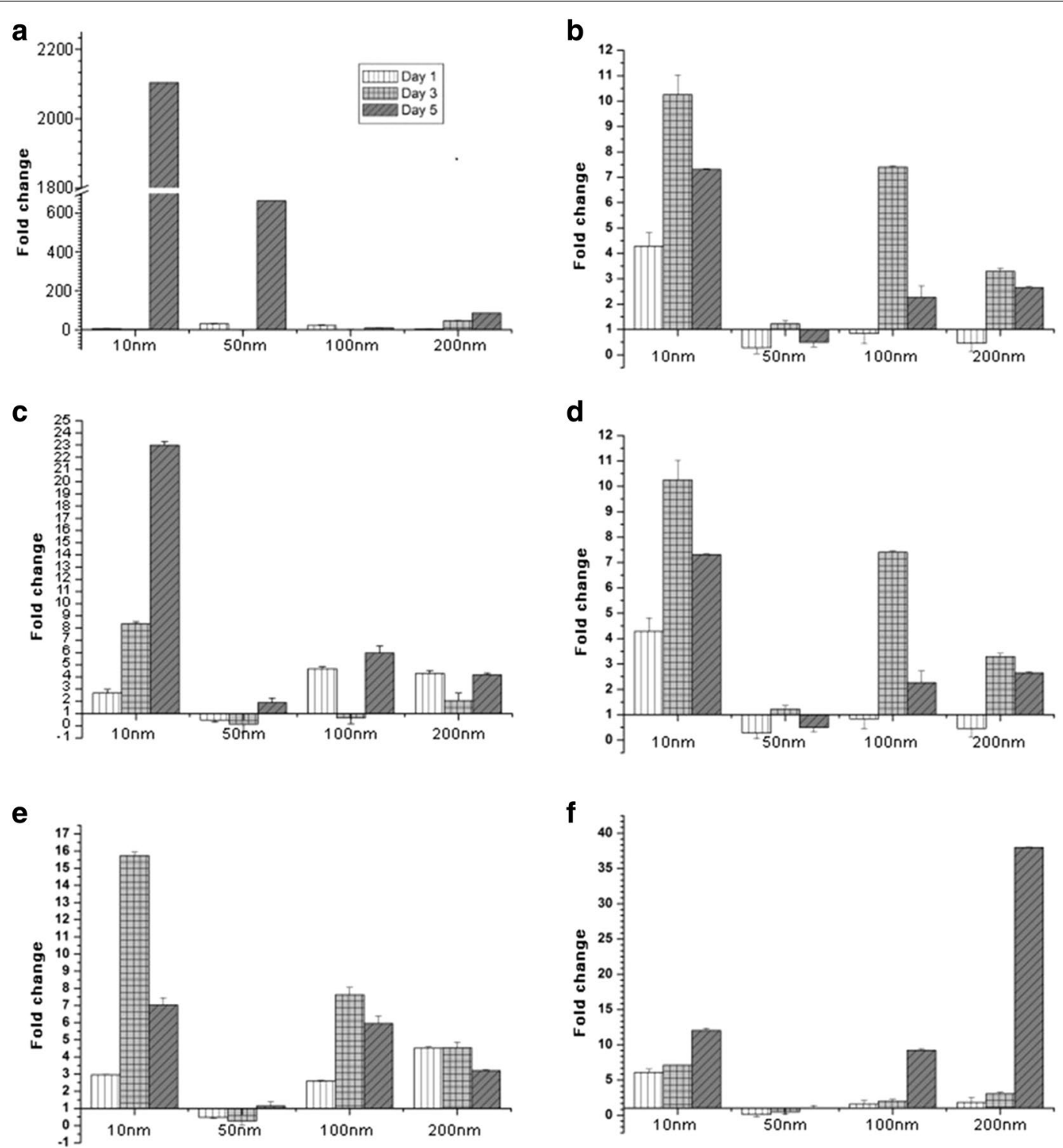

Fig. 4 Expression of iNOS genes in H9c2 on difference nanodots arrays by qPCR. H9c2 cells were cultured on flat, 10, 50, 100, and 200 nm nanodot arrays for day 1, 3, 5 before qPCR was performed. a TNF-a expression, $\mathbf{b}$ ILK expression, $\mathbf{c}$ Akt expression, $\mathbf{d}$ IKBa expression, e NFKB (p65), f iNOS expression. The mean \pm SD from at least 3 experiments is shown

controls the iNOS expression which in-turn is targeted by Akt/ILK/TNF- $\alpha$ [32]. This pathway also controls the NO secretion. In the eNOS pathway, G-Protein coupled receptor (GPCR) induces secondary signal transduction pathway after receiving signals from the cytoplasm. This causes the up-regulation of Phosphoinositide 3-kinase $(\mathrm{PI} 3 \mathrm{~K})$ which in-turn promotes the protein Kinase $\mathrm{B}$ (Akt) expression. This causes the down-regulation of expression levels of pro-apoptotic protein (Bad), B cell lymphoma-2, and NF-kB. The end result is the enhanced eNOS secretion.
The survival and physiological functions of the cardiomyocytes are regulated by the phosphoinositide 3-kinase (PI3K)-Akt signaling pathway, which is one of the eNOS signal transduction pathway [33]. It has been previously shown that eNOS plays an important role in the molecular mechanisms of the development of heart disease, myocardial ischemia/reperfusion injury [34, 35].

Western blot of key genes associated with NO secretion (Akt, eNOS, iNOS, p65) was performed. In our findings, expression profiles of Akt and p65 showed no apparent pattern. However, the expression of Akt were 
globally enhanced after day 3 and day 5 incubation periods. eNOS expression profiles were highly consistent with the Nitric oxide secretion like we showed in our previous result (Fig. 5a). eNOS was highly expressed for $200 \mathrm{~nm}$ after incubation for day 1 whereas 100, $50 \mathrm{~nm}$ stimulated maximum eNOS expression after incubation for day 3 and day 5 (Figs. 5b, 6). iNOS expression profiles did not show much resemblance with the NO secretion (Fig. 5c). Therefore, it is quite likely that the NO secretion of the cells grown on the nanodot arrays was dominated by the eNOS signaling pathway than by the iNOS pathway.

Furthermore, we checked the expression of p65 for day 1,3 and 5 . The activity of p65 was calculated by dividing the expression of p-p65 with the expression level of p65. The calculated p65 activity was roughly consistent with the NO secretion. It showed high activity for $200 \mathrm{~nm}$ for day 1 and later showed a size dependent expression (Fig. 5d).

\section{Discussions}

Nitric oxide is a unique signaling messenger in cardiomyocytes [36]. Various research groups have studied its vasodilation effects [37] and regulation of the platelet aggregation in the past [38]. Meanwhile, NO molecules can also promote the expression of pro-angiogenic cytokines, favorable for angiogenesis [39]. Therefore, modulation in level of $\mathrm{NO}$ by cardiomyocytes in response to a vascular implant is of great interest to the engineers. Nanosurfaces have been seen to stimulate and modulate the NO secretion [40]. However, a size and time based study of the modulation in NO secretion in response to different sized nanosurfaces has not been done before. Here, we provided the evidence for the first time that nanodot arrays of different sizes can stimulate the NO release to a different extent in rat cardiomyocytes cell line H9c2 (Fig. 2). Our results from day 1 showed that the cardiomyocytes display a size dependent production of $\mathrm{NO}$ with $200 \mathrm{~nm}$ arrays showing the maximum production and $50 \mathrm{~nm}$, the least. This proves that the cells respond differently to different nanodot arrays by secreting different amounts of NO (Fig. 2). To study the modulation in NO secretion by the cells in response to different nanodot arrays over time, we measured the NO secretion profile over 5 days. Our observations from day 3 and day 5 showed that the cardiomyocytes not only have a size-dependence with the nanodot array but also a time dependent relation (Fig. 2). Variation in cell characteristics in response to different surface roughness and geometry has been shown before [41-43]. In the present study, we measured the cardiomyocyte response to the nanodot arrays of size ranging from 10 to $200 \mathrm{~nm}$. We attempted to fabricate $5 \mathrm{~nm}$ nanodot arrays as well. However, their average size was fairly close to $10 \mathrm{~nm}(7 \mathrm{~nm})$ and therefore, we decided to exclude it from our study. In our previous studies, we have already studied the modulation of characteristics of $\mathrm{H} 9 \mathrm{c} 2$ in response to nanodot arrays [3]. Our findings in the past showed that with the increase in the size of the nanodots, the cell density decreases along with apoptosis like appearance followed by decreased number of focal adhesions which individually as well as together, are indicator of unhealthy cells. Hence, nanodot arrays from 10 to $200 \mathrm{~nm}$ were chosen as the size limits for the experiments in this study.

Secondly, to elucidate the signaling pathway responsible for the regulation and shifting of NO secretion over the subsequent days, we performed q-PCR of GPCR, PI3 K, Akt, Bad, Bcl-2, NF-KB, responsible for the eNOS expression (Fig. 3) and of TNF- $\alpha$, ILK, Akt, IKB $\alpha$, NF-KB responsible for the iNOS expression (Fig. 4). BCL-2 is an anti-apoptotic member of family BCL-X. Activated BAD induces apoptosis by inhibiting BCL-2 [44] and BCL-2 has been seen to downregulate Transcription factor NF-kB [45]. eNOS triggers the expression of NO [46]. It has been seen that activated Pi3K/Akt signaling pathway can impair NF-kB signaling [47]. Our findings showed that the expression of genes triggering eNOS (Fig. 3) was highly consistent with the maximum NO secretion for all the days but the genes triggering iNOS were not found to be consistent with the NO secretion (Fig. 4). This made us reach the conclusion that for these nanodot arrays, the NO secretion is modulated by the eNOS signaling pathway. NO triggered by eNOS plays a vital role in regulating vasodilation, anti-thrombic actions, apoptosis [48]. Previous studies have shown that eNOS deficiency can cause cardiomyocytes apoptosis which can be a factor in causing congenital heart defects during development [49]. To further validate that the NO modulation in the cells was triggered by eNOS, we performed Western Blot of the protein expression of eNOS, iNOS and the genes triggering them (Fig. 5). The protein expression of eNOS was found to be consistent with NO secretion profile for all the time periods. However, iNOS was found to be inconsistent.

Surprisingly, we observed changes in the expression of iNOS as well as eNOS. We found that for day 1 , eNOS modulates the NO expression in the cardiomyocytes. However, for the subsequent days, NO has a negative regulatory effect on the eNOS and iNOS expression as shown in the previous studies [50-53]. As one may notice, the highest eNOS expression on day 1 results in the highest NO secretion (Fig. 2). However, the high concentration of NO causes the decreased eNOS expression on day 3 for $200 \mathrm{~nm}$. Similar results were obtained on comparing the NO secretion profile (Fig. 2) and eNOS protein expression (Fig. 5b) for subsequent days. 

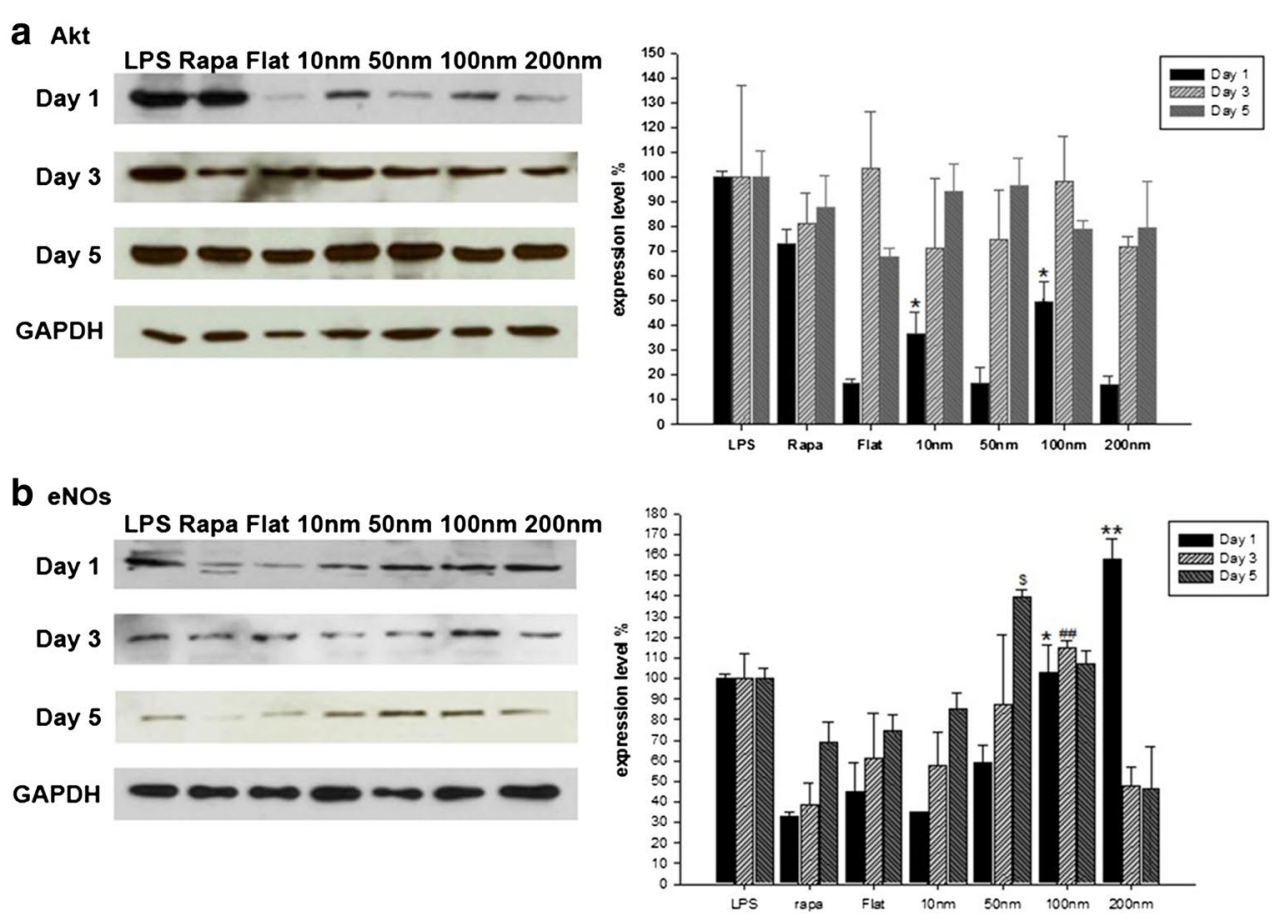

\section{C iNOs}
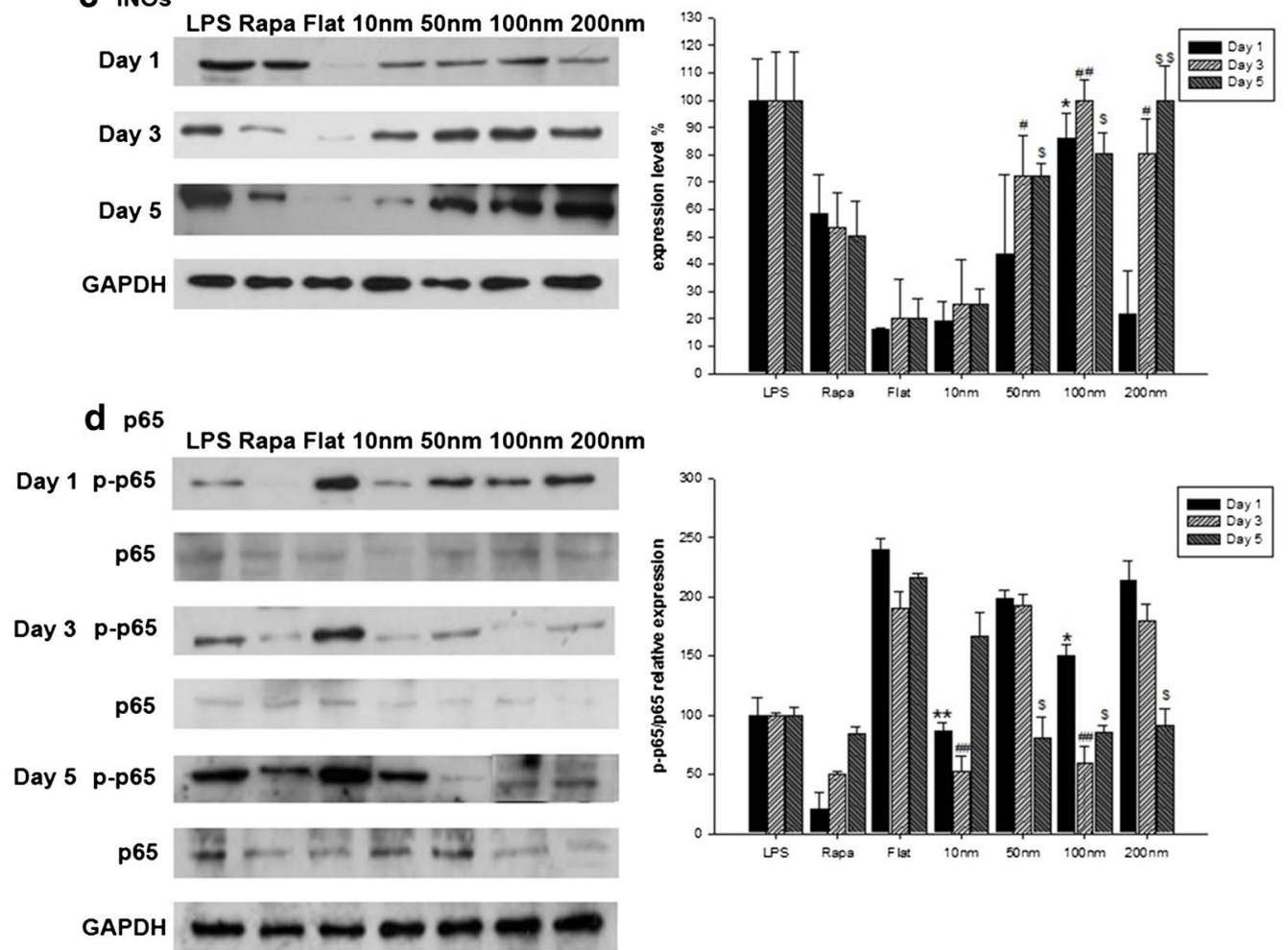

Fig. 5 Western Blot results of NO related proteins. a The Akt protein expression level was upregulated on 10, $100 \mathrm{~nm}$ nanodot arrays after day 1 incubation. b The eNOS expression levels were significantly enhanced on 200, 100 and $50 \mathrm{~nm}$ nanodot arrays after day 1,3,5 incubation. cThe iNOS expression levels were upregulated on $100 \mathrm{~nm}$ nanodot arrays after 1 day incubation and on 50, 100, $200 \mathrm{~nm}$ nanodot arrays for day 3, 5 incubation. d The activities of NF-kB-p65 (p-p65/p65) were downregulated on 10 and $100 \mathrm{~nm}$ nanodot arrays for day 1, 3 incubation period and were downregulated on 50, 100 and $200 \mathrm{~nm}$ nanodot arrays after incubation for day 5. ${ }^{*}$ shows $p<0.05$, while ** shows $p<0.01$. The mean \pm SD from at least 3 experiments is shown 


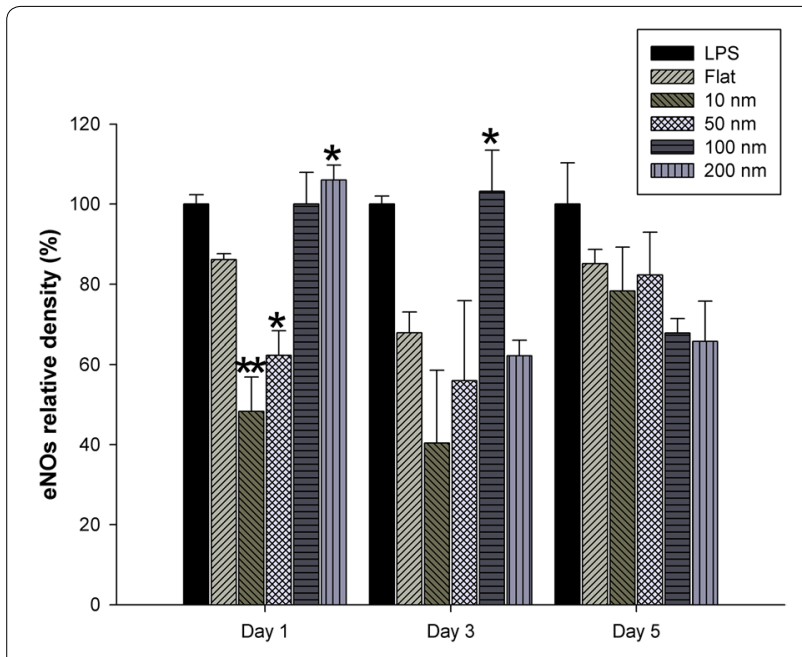

Fig. 6 eNOS relative density over different days

This showed that NO as well as eNOS play a very crucial role in regulating each other. Similar observations can be made from the western blot expression of iNOS and NO secretion. NO has a negative regulatory effect on the iNOS expression (Fig. 5c). On day 1, maximum NO secretion was observed for $200 \mathrm{~nm}$ nanodot arrays (Fig. 2). This causes the decreased expression of iNOS on day 1 Similar results were obtained on comparing the NO secretion profile (Fig. 2) and iNOS protein expression (Fig. 5c) for subsequent days. Even though our data suggests that nanodot arrays can alter the eNOS and iNOS genes, nevertheless, more experiments need to be done to elucidate their relative upregulation/downregulation (Fig. 7).

Due to their strength, flexibility and based on their biocompatibility, nanomaterials are continuously exploited to make vascular stents. Stents serve the purpose of keeping a blood vessel open and are therefore employed to treat Coronary heart disease like Atherosclerosis. In the past decade, properties of multiple materials have been studied for application in the field of Biomedical engineering. Out of these, Titanium (Ti), stainless steel, alloy of Cobalt-Chromium have been extensively studied due to their mechanical and biocompatible properties [54, 55]. Alloy of Cobalt-Chromium-Molybdenum provide better wear resistance [56]. Use of Tantalum (Ta) as an implant material has also been studied in the past due to its excellent X-Ray visibility and low magnetic susceptibility due to which it is often used as X-ray markers for stents [57]. Nevertheless, stents have been observed to undergo narrowing due to VSMC proliferation in response to injury at the time of stent implantation [58, 59]. Use of $\mathrm{Ti}$ as a sent has been widely studied by many researchers in the past. In 2008 Karla et al. studied the

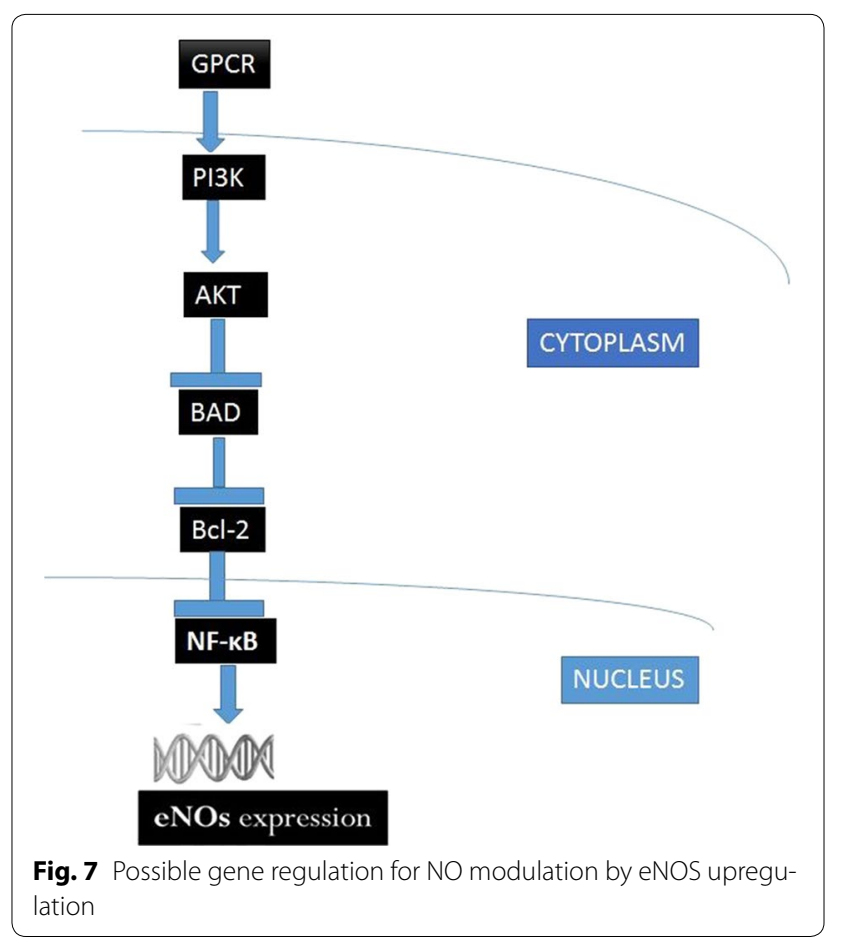

interactions between Bovine Aortic endothelial cells and Titanium dioxide $\left(\mathrm{TiO}_{2}\right)$ nanotubes along with flat $\mathrm{Ti}$ surfaces and observed better focal adhesions, high ECM, unidirectional actin and enhanced lamellipodia formation along with higher $\mathrm{NO}$ secretion in contrast to flat $\mathrm{Ti}$ surfaces which proves the ability of the nanotopography to control the cell characteristics and NO secretion [40]. A similar study was performed by Margherita et al. [60] to elucidate the effect of $\mathrm{TiO}_{2}$ nanotopography in the differentiation process of PC12 cells and the involvement of NOS and eERK in the same.

In summary, the present study exploited the use of Tantalum oxide nanodot arrays (Fig. 1) as a potential material for making cardiac stents by measuring the NO release in response to the nanodots as a measure of size and time (Fig. 2). Modulation in the expression of key genes regulating the NO release was also elucidated (Figs. 3, 4). Western Blot was performed to study the protein expression of key genes responsible for the modulation of $\mathrm{NO}$ (Fig. 5). The modulation was attributed to eNOS (Fig. 6). We also observed the negative regulatory effect of $\mathrm{NO}$ on eNOS and iNOS (Fig. 5) which is consistent with the previous studies.

These results prove an effective way to modulate the $\mathrm{NO}$ expression in cardiomyocytes on coming in contact with a cardiac implant. The modulation of $\mathrm{NO}$ by the implant will have a high degree of impact on the health of the heart cells of the patients. Moreover, the activation of eNOS has also been shown in previous studies to provide 
atheroprotection [61]. Hence, these findings will be of great importance in designing the surface of the implants within the fields of biomaterial and tissue engineering.

\section{Conclusions}

In the present study we have shown that the nano-topography modulates the NO secretion levels in a time as well as size dependent manner in the rat heart cell line H9c2. The stimulation of NO secretion by the nanodot arrays was found to shift from $200 \mathrm{~nm}$ on day 1 to $50 \mathrm{~nm}$ on day 5 (Fig. 2). We also attempted to identify the genes responsible for the NO secretion in response to our nanodot arrays with the help of q-PCR. Our findings show that the expressions of Bad, p65, eNOS were consistent with the NO secretion over different days. The eNOS protein expression was consistent with the NO secretion profile over different days supporting the q-PCR data of the eNOS genes (Fig. 5). The iNOS expression level was not found to be consistent with the NO secretion. This led us to conclude that the NO secretion in the cardiomyocytes cultured over the nanodot arrays is primarily regulated by the eNOS signaling pathway rather than the iNOS pathway. In addition, $\mathrm{NO}$ was also found to have a negative regulatory effect on the eNOS as well as iNOS expression.

According to the results in this study, the $50,100 \mathrm{~nm}$ nanodot arrays can be the suitable nanotopography pattern for heart stent design. These two nanodot surfaces promote NO secretion which can increase the vascular smooth muscle relaxation at the same time. The results of this study can improve the heart stent design in the medical treatments.

\section{Methods}

\section{Chemicals}

Lipopolysaccharide (LPS), Rapamycin, Trypsin were purchased from Sigma-Aldrich (USA). Bovine serum albumin (BSA) was purchased from GIBCO (Thermo Fisher Scientific Inc. USA). Phosphate buffered saline (PBS) was purchased from Bio-tech (Taipei, Taiwan). Sulfuric acid $\left(\mathrm{H}_{2} \mathrm{SO}_{4}\right)$, oxalic acid $\left(\mathrm{H}_{2} \mathrm{C}_{2} \mathrm{O}_{4}\right)$, and phosphoric acid $\left(\mathrm{H}_{3} \mathrm{PO}_{4}\right)$ were purchased from Sigma Chemicals (Perth, Western Australia), 6-inch silicon wafers, Aluminum ingots were purchased from Admat-Midas (Norristown, PA, USA). Other chemicals of analytical grade or higher were purchased from Sigma or Merck (USA).

\section{Fabrication of nanodot arrays}

Nanodot arrays were fabricated as previously described [3]. A 200-nm-thick tantalum nitride (TaN) thin film was sputtered onto a 6-in silicon wafer (Summit-Tech, West Hartford, CT, USA) followed by deposition of $3 \mu \mathrm{M}$-thick aluminum onto the top of a TaN layer by thermal coater.
Highly uniform nanodot arrays were fabricated from 10 to $200 \mathrm{~nm}$. Nanodot arrays of size smaller than $10 \mathrm{~nm}$ could not be fabricated due to technical limitation. Anodization was carried out in $1.8 \mathrm{M}$ sulfuric acid at $5 \mathrm{~V}$, $90 \mathrm{~min}$ for the $10 \mathrm{~nm}$ nanodot array and in $0.3 \mathrm{M}$ oxalic acid at $25 \mathrm{~V}, 90 \mathrm{~min}$ for the $50 \mathrm{~nm} .100$ and $200 \mathrm{~nm}$ nanodot arrays were fabricated by a two-step anodization method. In the first anodic oxidation step, anodization was carried out in $0.3 \mathrm{M}$ oxalic acid at 40 Volts, $10 \mathrm{~min}$, for $100 \mathrm{~nm}$ nanodot array and in $5 \%(\mathrm{w} / \mathrm{v}) \mathrm{H}_{3} \mathrm{PO}_{4}$ at $100 \mathrm{~V}, 5 \mathrm{~min}$, for $200 \mathrm{~nm}$ nanodot arrays. The porous alumina was removed by immersion in $5 \%(\mathrm{w} / \mathrm{v}) \mathrm{H}_{3} \mathrm{PO}_{4}$ for 70 and $60 \mathrm{~min}$ for 100 and $200 \mathrm{~nm}$ nanodot arrays, respectively. Second anodization step is repeated in the same way. Porous anodic alumina was formed during the anodic oxidation. The porous alumina was removed by immersing in $5 \%(\mathrm{w} / \mathrm{v}) \mathrm{H}_{3} \mathrm{PO}_{4}$ overnight. The dimensions and homogeneity of nanodot arrays were measured and calculated from images taken by JEOL JSM-6500 TFE-SEM. A thin layer of platinum was sputtered onto the structure.

\section{Cell culture}

To eliminate possible contamination of nano/micro particles, H9c2 cells were cultured in Dulbecco's Modified Eagle's Medium complimented with $10 \%$ FBS and $5 \%$ $\mathrm{CO}_{2}$ and incubated at $37^{\circ} \mathrm{C}$. The cell culturing was performed in a class- 10 clean room.

\section{Nitrite (NO) assay (Griess reagent system)}

Griess reagent system was purchased from Promega. Cells $\left(5 \times 10^{3}\right.$ cells $\left./ \mathrm{cm}^{2}\right)$ were seeded on different nanodot arrays (flat, 10, 50, 100, $200 \mathrm{~nm}$ ). Production of NO was assayed by measuring the stable metabolite of nitrite levels in the culture medium. Dispense $50 \mu \mathrm{L}$ of the $1 \%$ Sulfanilamide Solution to all experimental samples and incubate for 5-10 $\mathrm{min}$ at room temperature, protected from light. Then dispense $50 \mu \mathrm{L}$ of the NED Solution (0.1 \% naphthylethylenediamine dihydrochloride/2 \% $\mathrm{H}_{3} \mathrm{PO}_{4}$ ) and incubate at $25^{\circ} \mathrm{C}$ for $10 \mathrm{~min}$. The absorbance at $550 \mathrm{~nm}$ was measured with UV-spectrophotometer.

\section{Quantitative real-time PCR}

The quantitative Real time PCR was performed to investigate the nanotopographic effects on the gene expression level. Oligo primers of the genes (TNF-a, ILK, AKT, IKB $\alpha$, p65, iNOS, GPCR, PI3 K, Bad, Bcl-2, eNOS) are listed in the Table 1 [46, 47, 62-66]. $0.5 \mu \mathrm{g} / \mu \mathrm{L}$ LPS with hours 3 pre-treatment was used as a positive control. $100 \mathrm{nM}$ Rapamycin for hours 2 was used as a negative control group. The specificity of primers was verified with polymerase chain reaction with $\mathrm{H} 9 \mathrm{c} 2$ reverse transcribed mRNA as a template. 
Table 1 Primer sequence used for RT-PCR

\begin{tabular}{|c|c|c|}
\hline Gene name & Forward & Reverse \\
\hline TNF-a & TCTGTCTACTGAACTTCGGGGTGAT & CAGCCTTGTCCCTTGAAGAGAACC \\
\hline GPCR & GCGCGGATCCGCCACGATGCTTGTCCTGCG & GCGCGAATTCTTAGGAGCTTAGTCTACAAACTG \\
\hline ILK & GCTCAACTTTCTGGCAAAGC & TGTGGCAAGTGACAAAGCTC \\
\hline $\mathrm{PI3K}$ & TGACGCTTTCAAACGCTATC & CAGAGAGTACTCTTGCATT \\
\hline Akt & GTGCTGGAGGACAACGACT & GTGTAGGGTCCTTCTTGAGCA \\
\hline $\mathrm{IKBa}$ & GACGAGGATTACGAGCAGAT & CCTGGTAGGTTACTCTGTTG \\
\hline Bad & CCCCCCAATCTCTGGGCAGCG & TCACTGGGAGGGATGGA \\
\hline $\mathrm{BCl}-2$ & GCTACGAGTGGGATACTGG & GTGTGCAGATGCCGGTTCA \\
\hline p65 & CATTGAGGTGTATTTCACGG & GAACACAATGGCCACTTGCC \\
\hline eNOs & TGGCAGCCCTAAGACCTATG & AGTCCGAAAATGTCCTCGTG \\
\hline iNOs & CTGCATGGAACAGTATAAGGCAAAC & AGACAGTTTCTGGTCGATGTCATGA \\
\hline
\end{tabular}

All sequences are from $5^{\prime}$ to $3^{\prime}$

Total RNA was extracted from $5 \times 10^{3}$ cells using TRIreagent (Talron Biotech) according to the manufacturer's specifications. The RNA was isolated using $200 \mu \mathrm{L}$ chloroform extraction and isopropanol precipitation. The RNA extract was immediately purified using an RNeasy Mini Kit (Qiagen) to remove impurities and unwanted organic compounds. Purified RNA was re-suspended in DEPC-treated water and quantified by OD260. The OD260-to-OD280 ratio usually exceeded 2.0 at this stage. For cDNA synthesis, $29 \mu \mathrm{L}$ total RNA was annealed using $1 \mu \mathrm{g}$ oligo-dT primer, followed by reverse transcription using SuperScript-III Reverse Transcriptase (Invitrogen) in a total volume of $50 \mu \mathrm{L}$. Between 0.2 and $0.5 \mu \mathrm{L}$ of the reverse transcription reactions were used for quantitative qPCR using SYBR Green I performed on an iCycler iQ5 (Bio-Rad Laboratories). The cycling conditions were as follows: 1 cycle of $5 \mathrm{~min}$ at $95^{\circ} \mathrm{C}$ and 50 cycles of $20 \mathrm{~s}$ at $95{ }^{\circ} \mathrm{C}, 20 \mathrm{~s}$ at $55^{\circ} \mathrm{C}$, and $40 \mathrm{~s}$ at $72{ }^{\circ} \mathrm{C}$. Fluorescence was measured after each $72{ }^{\circ} \mathrm{C}$ step. Expression levels were obtained using threshold cycles $(\mathrm{Ct})$ that were determined by the iCycler iQ Detection System software. Relative transcript quantities were calculated using the $\Delta \Delta \mathrm{Ct}$ method. The gene GAPDH was used as a reference gene and was amplified along with the target genes from the same cDNA samples. The difference in threshold cycles of the sample mRNA relative to GAPDH mRNA was defined as the $\Delta \mathrm{Ct}$. The difference between the $\Delta \mathrm{Ct}$ of the control flat and the $\Delta \mathrm{Ct}$ of the cells grown on nanodot arrays was de fined as the $\Delta \Delta \mathrm{Ct}$. The fold change in mRNA expression was expressed as $2 \Delta \Delta \mathrm{Ct}$. The results were expressed as the mean SD of six experiments.

\section{Protein extraction and Western blot analysis}

Total protein was extracted from $5 \times 10^{3}$ cells using lysis buffer. Ultrasound was applied using a sonicator operating the sample $6 \mathrm{~min}$ at $4{ }^{\circ} \mathrm{C}$. Cultured H9c2 cardiomyocytes were lysed and centrifuged at $3000 \mathrm{rpm}$ for $2 \mathrm{~min}$. The supernatants were transferred to new Eppendorf tubes and protein concentrations were defined using UV/VIS spectroscopy $(595 \mathrm{~nm})$. After the protein concentrations were defined, solutions were mixed with $5 \mathrm{X}$ sample buffer and lysis buffer to a final concentration of $1 \mathrm{mg} / \mathrm{ml}$. Samples were heated at $95{ }^{\circ} \mathrm{C}$ for $3 \mathrm{~min}$ and cooled at $4{ }^{\circ} \mathrm{C}$ for $3 \mathrm{~min}$, which was repeated three times. Proteins were separated using $10 \%$ SDS-PAGE gels and transferred to PVDF membranes. Non-specific protein binding was blocked by a $5 \%$ milk solution for hours 2 . The membranes were subsequently blotted at $4{ }^{\circ} \mathrm{C}$ overnight with the following primary monoclonal antibodies: (1) anti-eNOS (1:1000; Abcam); (2) anti-iNOS (1:500; Abcam); (3) anti-p65 (1:250; Genetex); (4) Anti-phosphoNFkB p65(Ser536) (1:1000; cell signaling); (5) antiAkt;(6) GPPDH (1:200; Abcam), which were diluted in blocking buffer. Specific primary anti-bodies were blotted using second antibodies $(1: 10,000)$ in the blocking buffer at room temperature for hours 2. Chemiluminescent detection was performed using western blotting luminol reagent and oxidizing reagent (USA). To compare the different groups, densitometric quantification was performed only on equally processed blots. Bands on Western blots were analyzed with a Scan Jet 3390 computing densitometer using IMAGE J software. Relative densities of immunoreactive bands were normalized to the density of corresponding bands for GAPDH. The results were expressed as the mean SD of three experiments.

\section{Statistics}

The results are expressed as the mean $\pm \mathrm{SD}$ of three experiments. Student's t test was employed to determine data sets that differed significantly from one another, and significance was defined as a p value $<0.05$; highly significance was defined as a $\mathrm{p}$ value $<0.01$. 


\section{Abbreviations}

AAO: anodic aluminum oxide; CDNA: complementary DNA; eNOS: endothelial nitric oxide synthase; iNOS: inducible nitric oxide synthase; LPS: lipopolysaccharide; nm: nanometer; nNOS: neuronal nitric oxide synthase; SD: standard deviation; NO: nitric oxide; OD: optical density; PBS: phosphate buffered saline; PI3K: phosphoinositide 3-kinase; PVDF: polyvinylidene fluoride; q-PCR: quantitative polymerase chain reaction; Rpm: revolutions per minute; RT-PCR: reverse transcriptase polymerase chain reaction; TaN: tantalum nitride.

\section{Authors' contributions}

UD carried out the entire fabrication and Nitric Oxide sensing experiments and drafted the manuscript. CHL carried out the q-PCR experiments and carried out the statistical analysis of the results. $\mathrm{CCH}$ carried out the Western Blot experiments. YHC and GSH provided the facilities necessary to carry out the fabrication process and analyzed the fabrication results. YRL provided the cell line for the experiments. WLC analyzed, verified all of the experimental data and the Manuscript. UD, YHC, YRL, GSH and WLC were involved in the design of this study. All authors read and approved the final manuscript.

\section{Author details}

${ }^{1}$ Department Material Science and Technology, National Chiao Tung University Hsinchu, 1001 University Road, Hsinchu 300, Taiwan, ROC. ${ }^{2}$ Hokan Life Technology, F2, 793 Fu-Ke Road, Taichung, Taiwan, ROC. ${ }^{3}$ Department of Emergency Medicine, Changhua Christian Hospital, 135 Nanshiao Street, Changhua 500, Taiwan. ${ }^{4}$ Department of Biological Science and Technology, National Chiao Tung University Hsinchu, 1001 University Road, Hsinchu 300, Taiwan, ROC

\section{Acknowledgements}

This work was supported by the National Science Council, Taiwan, Republic of China (grants 101-2314-B-009-001, and 102-2314-B-009-001).

\section{Competing interests}

The authors declare that they have no competing interests.

Received: 12 August 2015 Accepted: 29 October 2015

Published online: 09 November 2015

\section{References}

1. Lee $\mathrm{CH}$, Cheng YW, Huang GS. Topographical control of cell-cell interaction in C6 glioma by nanodot arrays. Nanoscale Res Lett. 2014;9:250.

2. Pan HA, Hung YC, Su CW, Tai SM, Chen CH, Ko FH, Huang GS. A nanodot array modulates cell adhesion and induces an apoptosis-like abnormality in NIH-3T3 cells. Nanoscale Res Lett. 2009:4:903-12.

3. Pan HA, Hung YC, Sui YP, Huang GS. Topographic control of the growth and function of cardiomyoblast $\mathrm{H} 9 \mathrm{c} 2$ cells using nanodot arrays. Biomaterials. 2012;33:20-8.

4. Pan HA, Liang JY, Hung YC, Lee $\mathrm{CH}$, Chiou JC, Huang GS. The spatial and temporal control of cell migration by nanoporous surfaces through the regulation of ERK and integrins in fibroblasts. Biomaterials. 2013;34:841-53.

5. Yang $L$, Sheldon BW, Webster TJ. The impact of diamond nanocrystallinity on osteoblast functions. Biomaterials. 2009;30:3458-65.

6. Lu J, Yao C, Yang L, Webster TJ. Decreased platelet adhesion and enhanced endothelial cell functions on nano and submicron-rough titanium stents. Tissue Eng Part A. 2012;18:1389-98.

7. Schmidt M, Nazneen F, Georgiev Y, Herzog G, Galvin P, Petkov N. FIB patterning of stainless steel for the development of nano-structured stent surfaces for cardiovascular applications. J Phys Conf. 2012;371(1):012065.

8. Clark P, Connolly P, Curtis AS, Dow JA, Wilkinson CD. Topographical control of cell behaviour. I. Simple step cues. Development. 1987;99:439-48.

9. Teixeira Al, Abrams GA, Bertics PJ, Murphy CJ, Nealey PF. Epithelial contact guidance on well-defined micro- and nanostructured substrates. J Cell Sci. 2003:116:1881-92.

10. Tsai WB, Lin JH. Modulation of morphology and functions of human hepatoblastoma cells by nano-grooved substrata. Acta Biomater. 2009;5:1442-54.
11. Wang PY, Yu JS, Lin JH, Tsai WB. Modulation of alignment, elongation and contraction of cardiomyocytes through a combination of nanotopography and rigidity of substrates. Acta Biomater. 2011;7:3285-93.

12. Nazneen F, Herzog G, Arrigan DWM, Caplice N, Benvenuto P, Galvin P, Thompson M. Surface chemical and physical modification in stent technology for the treatment of coronary artery disease. J Biomed Mater Res B Appl Biomater. 2012;100b:1989-2014.

13. Kim DH, Kshitiz, Smith RR, Kim P, Ahn EH, Kim HN, Marban E, Suh KY, Levchenko A. Nanopatterned cardiac cell patches promote stem cell niche formation and myocardial regeneration. Integr Biol. 2012;4:1019-33.

14. Kim DH, Lipke EA, Kim P, Cheong R, Thompson S, Delannoy M, Suh KY, Tung L, Levchenko A. Nanoscale cues regulate the structure and function of macroscopic cardiac tissue constructs. Proc Natl Acad Sci USA. 2010;107:565-70.

15. Park J, Bauer S, Schlegel KA, Neukam FW, von der Mark K, Schmuki P. TiO nanotube surfaces: $15 \mathrm{~nm}$-an optimal length scale of surface topography for cell adhesion and differentiation. Small. 2009;5:666-71.

16. Davidson P, Bigerelle M, Bounichane B, Giazzon M, Anselme K. Definition of a simple statistical parameter for the quantification of orientation in two dimensions: application to cells on grooves of nanometric depths. Acta Biomater. 2010;6:2590-8.

17. Brammer KS, Oh S, Cobb CJ, Bjursten LM, van der Heyde $H$, Jin S Improved bone-forming functionality on diameter-controlled $\mathrm{TiO}_{2}$ nanotube surface. Acta Biomater. 2009;5:3215-23.

18. Okada S, Ito H, Nagai A, Komotori J, Imai H. Adhesion of osteoblast-like cells on nanostructured hydroxyapatite. Acta Biomater. 2010;6:591-7.

19. Anselme K, Bigerelle M. Topography effects of pure titanium substrates on human osteoblast long-term adhesion. Acta Biomater. 2005;1:211-22.

20. Mohiuddin M, Pan HA, Hung YC, Huang GS. Control of growth and inflammatory response of macrophages and foam cells with nanotopography. Nanoscale Res Lett. 2012;7:394.

21. Dalby MJ, Pasqui D, Affrossman S. Cell response to nano-islands produced by polymer demixing: a brief review. IEE Proc Nanobiotechnol. 2004;151:53-61.

22. Barthes J, Ozcelik H, Hindie M, Ndreu-Halili A, Hasan A, Vrana NE. Cell microenvironment engineering and monitoring for tissue engineering and regenerative medicine: the recent advances. Biomed Res Int 2014;2014:1-18.

23. Garg UC, Hassid A. Nitric oxide-generating vasodilators and 8-bromocyclic guanosine monophosphate inhibit mitogenesis and proliferation of cultured rat vascular smooth muscle cells. J Clin Invest. 1989:83:1774-7.

24. Tsai KL, Huang YH, Kao CL, Yang DM, Lee HC, Chou HY, Chen YC, Chiou GY, Chen LH, Yang YP, et al. A novel mechanism of coenzyme Q10 protects against human endothelial cells from oxidative stress-induced injury by modulating NO-related pathways. J Nutr Biochem. 2012;23:458-68.

25. Bredt DS, Snyder SH. Nitric oxide: a physiologic messenger molecule. Annu Rev Biochem. 1994:63:175-95.

26. Gimbrone MA Jr. Endothelial dysfunction and atherosclerosis. J Card Surg. 1989;4:180-3

27. Gimbrone MA Jr, Topper JN, Nagel T, Anderson KR, Garcia-Cardena G. Endothelial dysfunction, hemodynamic forces, and atherogenesis. Ann N Y Acad Sci. 2000;902:230-9 (discussion 239-240)

28. Grange RW, Isotani E, Lau KS, Kamm KE, Huang PL, Stull JT. Nitric oxide contributes to vascular smooth muscle relaxation in contracting fasttwitch muscles. Physiol Genomics. 2001;5:35-44.

29. Zhao MZ, Wang QS, Lai WJ, Zhao XY, Shen HY, Nie FL, Zheng YF, Wei SC, I ل JG. In vitro bioactivity and biocompatibility evaluation of bulk nanostructured titanium in osteoblast-like cells by quantitative proteomic analysis. J Mater Chem B. 2013;1:1926-38.

30. Kolpakov V, Gordon D, KulikTJ. Nitric oxide-generating compounds inhibit total protein and collagen-synthesis in cultured vascular smoothmuscle cells. Circ Res. 1995;76:305-9.

31. Pu QH, Zhuang DM, Thakran S, Hassid A. Mechanisms related to NOinduced motility in differentiated rat aortic smooth muscle cells. Am J Physiol Heart Circ Physiol. 2011;300:H101-8.

32. Wehling M, Spencer MJ, Tidball JG. A nitric oxide synthase transgene ameliorates muscular dystrophy in mdx mice. J Cell Biol. 2001;155:123-31.

33. Mori M, Gotoh T. Regulation of nitric oxide production by arginine metabolic enzymes. Biochem Biophys Res Commun. 2000;275:715-9. 
34. Hausenloy DJ, Yellon DM. Reperfusion injury salvage kinase signalling: taking a RISK for cardioprotection. Heart Fail Rev. 2007;12:217-34.

35. Matsui T, Rosenzweig A. Convergent signal transduction pathways controlling cardiomyocyte survival and function: the role of PI 3-kinase and Akt. J Mol Cell Cardiol. 2005;38:63-71.

36. Ignarro LJ. Nitric oxide as a unique signaling molecule in the vascular system: A historical overview. J Physiol Pharmacol. 2002;53:503-14.

37. Kingwell BA. Nitric oxide-mediated metabolic regulation during exercise: effects of training in health and cardiovascular disease. Faseb J. 2000;14:1685-96.

38. Freedman JE, Parker C, Li LQ, Perlman JA, Frei B, Ivanov V, Deak LR, lafrati MD, Folts JD. Select flavonoids and whole juice from purple grapes inhibit platelet function and enhance nitric oxide release. Circulation. 2001;103:2792-8

39. Berardi GRM, Rebelatto CK, Tavares HF, Ingberman M, Shigunov P, Barchiki F, Aguiar AM, Miyague NI, Francisco JC, Correa A, et al. Transplantation of SNAP-treated adipose tissue-derived stem cells improves cardiac function and induces neovascularization after myocardium infarct in rats. Exp Mol Pathol. 2011;90:149-56.

40. Brammer KS, Oh S, Gallagher JO, Jin S. Enhanced cellular mobility guided by $\mathrm{TiO}_{2}$ nanotube surfaces. Nano Lett. 2008;8:786-93.

41. Gittens RA, McLachlan T, Olivares-Navarrete R, Cai Y, Berner S, Tannenbaum R, Schwartz Z, Sandhage KH, Boyan BD. The effects of combined micron-/submicron-scale surface roughness and nanoscale features on cell proliferation and differentiation. Biomaterials. 2011;32:3395-403.

42. Silva TSN, Machado DC, Viezzer C, Silva AN, de Oliveira MG. Effect of titanium surface roughness on human bone marrow cell proliferation and differentiation. An experimental study. Acta Cir Bras. 2009;24:200-5.

43. Toh YC, Xing JW, Yu HR. Modulation of integrin and E-cadherin-mediated adhesions to spatially control heterogeneity in human pluripotent stem cell differentiation. Biomaterials. 2015;50:87-97.

44. Cheng EH, Wei MC, Weiler S, Flavell RA, MakTW, Lindsten T, Korsmeyer SJ. $\mathrm{BCL}-2, \mathrm{BCL}-\mathrm{X}(\mathrm{L})$ sequester $\mathrm{BH} 3$ domain-only molecules preventing $\mathrm{BAX}$ and BAK-mediated mitochondrial apoptosis. Mol Cell. 2001;8:705-11.

45. Grimm S, Bauer MKA, Baeuerle PA, SchulzeOsthoff K. BCl-2 downregulates the activity of transcription factor NF-kappa B induced upon apoptosis. J Cell Biol. 1996;134:13-23.

46. Kumar SD, Yong SK, Dheen ST, Bay BH, Tay SSW. Cardiac malformations are associated with altered expression of vascular endothelial growth factor and endothelial nitric oxide synthase genes in embryos of diabetic mice. Exp Biol Med. 2008;233:1421-32

47. Pan LL, Liu XH, Gong QH, Zhu YZ. S-Propargyl-cysteine (SPRC) attenuated lipopolysaccharide-induced inflammatory response in $\mathrm{H} 9 \mathrm{c} 2$ cells involved in a hydrogen sulfide-dependent mechanism. Amino Acids. 2011;41:205-15.

48. Forstermann U, Closs El, Pollock JS, Nakane M, Schwarz P, Gath I, Kleinert $\mathrm{H}$. Nitric-oxide synthase isozymes - characterization, purification, molecular-cloning, and functions. Hypertension. 1994;23:1121-31.

49. Feng QP, Song W, Lu XR, Hamilton JA, Lei M, Peng TQ, Yee SP. Development of heart failure and congenital septal defects in mice lacking endothelial nitric oxide synthase. Circulation. 2002;106:873-9.

50. Chang K, Lee SJ, Cheong I, Billiar TR, Chung HT, Han JA, Kwon YG, Ha KS, Kim YM. Nitric oxide suppresses inducible nitric oxide synthase expression by inhibiting post-translational modification of I kappa B. Exp Mol Med. 2004;36:311-24.
51. Buga GM, Griscavage JM, Rogers NE, Ignarro LJ. Negative feedback regulation of endothelial cell function by nitric oxide. Circ Res. 1993;73(5):808-12.

52. Katsuyama K, Shichiri M, Marumo F, Hirata Y. NO inhibits cytokineinduced iNOS expression and NF-kappa B activation by interfering with phosphorylation and degradation of I kappa B-alpha. Arterioscler Thromb Vasc Biol. 1998;18:1796-802.

53. Vaziri ND, Wang XQ. cGMP-mediated negative-feedback regulation of endothelial nitric oxide synthase expression by nitric oxide. Hypertension. 1999;34:1237-41.

54. Jayaraman M, Meyer U, Buhner M, Joos U, Wiesmann HP. Influence of titanium surfaces on attachment of osteoblast-like cells in vitro. Biomaterials. 2004;25:625-31.

55. O'Brien B, Carroll W. The evolution of cardiovascular stent materials and surfaces in response to clinical drivers: a review. Acta Biomater. 2009;5:945-58.

56. Saldivar-Garcia AJ, Lopez HF. Microstructural effects on the wear resistance of wrought and as-cast Co-Cr-Mo-C implant alloys. J Biomed Mater Res A. 2005;74a:269-74.

57. Aronson AS, Jonsson N, Alberius P. Tantalum markers in radiography —an assessment of tissue-reactions. Skeletal Radiol. 1985;14:207-11.

58. Palmaz JC. Intravascular stents in the last and the next 10 years. J Endovasc Ther. 2004;11:200-6.

59. Whittaker DR, Fillinger MF. The engineering of endovascular stent technology: a review. Vasc Endovascular Surg. 2006;40:85-94.

60. Tamplenizza M, Lenardi C, Maffioli E, Nonnis S, Negri A, Forti S, Sogne E, De Astis S, Matteoli M, Schulte C, et al. Nitric oxide synthase mediates PC12 differentiation induced by the surface topography of nanostructured $\mathrm{TiO}_{2}$. J Nanobiotechnol. 2013;11:35.

61. Sharma A, Sellers S, Stefanovic N, Leung C, Tan SM, Huet O, Granville DJ, Cooper ME, de Haan JB, Bernatchez P. Direct eNOS activation provides atheroprotection in diabetes-accelerated atherosclerosis. Diabetes. 2015;64(11):3937-50.

62. Kim HJ, Yu BP, Chung HY. Molecular exploration of age-related NFkappaB/IKK downregulation by calorie restriction in rat kidney. Free Radic Biol Med. 2002;32:991-1005.

63. Levrand S, Pesse B, Feihl F, Waeber B, Pacher P, Rolli J, Schaller MD, Liaudet L. Peroxynitrite is a potent inhibitor of NF-kappa B activation triggered by inflammatory stimuli in cardiac and endothelial cell lines. J Biol Chem. 2005:280:34878-87.

64. Mangi AA, Noiseux N, Kong DL, He HM, Rezvani M, Ingwall JS, Dzau VJ. Mesenchymal stem cells modified with Akt prevent remodeling and restore performance of infarcted hearts. Nat Med. 2003;9:1195-201.

65. Supavekin S, Zhang W, Kucherlapati R, Kaskel FJ, Moore LC, Devarajan P. Differential gene expression following early renal ischemia/reperfusion. Kidney Int. 2003;63:1714-24.

66. Wang BH, Shravah J, Luo HL, Raedschelders K, Chen DDY, Ansley DM. Propofol protects against hydrogen peroxide-induced injury in cardiac $\mathrm{H} 9 \mathrm{c} 2$ cells via Akt activation and Bcl-2 up-regulation. Biochem Biophys Res Commun. 2009;389:105-11.

\section{Submit your next manuscript to BioMed Central and take full advantage of:}

- Convenient online submission

- Thorough peer review

- No space constraints or color figure charges

- Immediate publication on acceptance

- Inclusion in PubMed, CAS, Scopus and Google Scholar

- Research which is freely available for redistribution

Submit your manuscript at

www.biomedcentral.com/submit
C Biomed Central 